\title{
Rates of molecular evolution and diversification in plants: chloroplast substitution rates correlate with species-richness in the Proteaceae
}

\author{
David Duchene ${ }^{*}$ and Lindell Bromham
}

\begin{abstract}
Background: Many factors have been identified as correlates of the rate of molecular evolution, such as body size and generation length. Analysis of many molecular phylogenies has also revealed correlations between substitution rates and clade size, suggesting a link between rates of molecular evolution and the process of diversification. However, it is not known whether this relationship applies to all lineages and all sequences. Here, in order to investigate how widespread this phenomenon is, we investigate patterns of substitution in chloroplast genomes of the diverse angiosperm family Proteaceae. We used DNA sequences from six chloroplast genes (6278bp alignment with 62 taxa) to test for a correlation between diversification and the rate of substitutions.

Results: Using phylogenetically-independent sister pairs, we show that species-rich lineages of Proteaceae tend to have significantly higher chloroplast substitution rates, for both synonymous and non-synonymous substitutions.

Conclusions: We show that the rate of molecular evolution in chloroplast genomes is correlated with net diversification rates in this large plant family. We discuss the possible causes of this relationship, including molecular evolution driving diversification, speciation increasing the rate of substitutions, or a third factor causing an indirect link between molecular and diversification rates. The link between the synonymous substitution rate and clade size is consistent with a role for the mutation rate of chloroplasts driving the speed of reproductive isolation. We find no significant differences in the ratio of non-synonymous to synonymous substitutions between lineages differing in net diversification rate, therefore we detect no signal of population size changes or alteration in selection pressures that might be causing this relationship.
\end{abstract}

Keywords: Phylogenetic, Substitution, Comparative analysis, Synonymous, Nonsynonymous, dN/dS, Reproductive isolation, Incompatibility

\section{Background}

Present biodiversity has come about through processes of diversification and extinction of species, and the mechanisms that drive these processes are a central focus in evolutionary biology (e.g. [1-4]). One intriguing relationship that has been revealed through studies of branch lengths on molecular phylogenies is a link between the rate of molecular evolution and the net diversification rate. A correlation between evolutionary rates and species diversity has been found in several groups

\footnotetext{
* Correspondence: david.duchene@anu.edu.au
Centre for Macroevolution and Macroecology, Evolution, Ecology \& Genetics,
Research School of Biology, Australian National University, Canberra, ACT

* Correspondence: david.duchene@anu.edu.au
Centre for Macroevolution and Macroecology, Evolution, Ecology \& Genetics,
Research School of Biology, Australian National University, Canberra, ACT

* Correspondence: david.duchene@anu.edu.au
Centre for Macroevolution and Macroecology, Evolution, Ecology \& Genetics,
Research School of Biology, Australian National University, Canberra, ACT 0200, Australia
}

(c) 2013 Duchene and Bromham; licensee BioMed Central Ltd. This is an Open Access article distributed under the terms of the Creative Commons Attribution License (http://creativecommons.org/licenses/by/2.0), which permits unrestricted use, distribution, and reproduction in any medium, provided the original work is properly cited. and other metazoan phyla, orders, and classes [9].

However, not all the datasets analysed have provided evidence for a link between diversification rates and rates of molecular evolution. One study of a large number of phylogenies found a relationship between root-to -tip branch lengths and net diversification in around half of the phylogenies tested, but it is not clear whether this was due to low power or lack of a common trend [10]. Another study examined genetic data within the mammals and found no evidence of an association between molecular rates and net diversification [11]. Accordingly, the universality and causes of the link remain uncertain.

There are three possible causes for the association between net diversification and the rate of molecular 
evolution [5,6]. One is that the process of diversification drives changes in the rate of molecular evolution. Speciation might influence the rate of molecular evolution through positive selection on particular genes associated with adaptation to novel niches [12]. Speciation could also cause genome-wide increases in substitution rate if speciation is typically associated with population subdivision $[13,14]$. This is because a reduction in effective population size $\left(N_{e}\right)$ can cause a higher rate of fixation of nearly neutral mutations (e.g. [15]), leading to a faster substitution rate [14].

Conversely, a higher rate of molecular evolution may increase the diversification rate. A faster mutation rate may hasten differentiation between populations and promote reproductive incompatibility [16]. For example, it has been suggested that higher standing genetic diversity in populations at low latitude may contribute to faster diversification in the tropics [17]. Increased standing genetic variation may produce more raw material for adaptation [18] or reduce the likelihood of extinction [19]. However, a recent study of orchids found no evidence for a link between population genetic variability and net diversification rate [20]. A higher rate of molecular evolution may increase the rate of diversification by accelerating the formation of hybrid incompatibility, occurring through the accumulation of genetic incompatibilities between the genomes of the diverging populations [16].

Alternatively, there might be a third factor that influences both the rate of molecular evolution and diversification rate, creating an indirect link between diversification and molecular evolution. For example, environmental energy (temperature and UV light) has been associated with both the diversification rate and the rate of molecular evolution in angiosperms [21]. Other potential third factors are life history features, such as size or generation length, which are linked with the rate of molecular evolution and diversification rates of angiosperms and several metazoan taxa [9,22-24]. It has also been suggested that both morphological and molecular rates of change may be connected to diversification rate [24]. Whether the correlation between rate of molecular evolution and net diversification has a causal or indirect effect needs more investigation.

One way of disentangling the potential causes of the observed relationship between diversification rate and rate of molecular evolution is to partition substitutions in protein-coding genes into synonymous and nonsynonymous substitutions. Synonymous mutations do not change the amino acid sequence of a protein and hence are expected to behave as neutral. If so, then the synonymous substitution rate $(\mathrm{dS})$ should reflect only the mutation rate [25]. Nonsynonymous mutations are expected to have a range of fitness effects, including neutral, positive and negative, so may be subject to both drift and selection. An increase in the nonsynonymous substitution rate $(\mathrm{dN})$ relative to the synonymous rate (dS) can occur through positive selection promoting the fixation of nonsynonymous mutations, or through a reduction in population size increasing the rate of fixation of nearly neutral mutations by drift.

The link between rate of molecular evolution and diversification rate has been attributed to the action of selection during speciation, or to a reduction in average population size in lineages undergoing diversification [14], both of which would be expected to increase the relative rate of nonsynonymous substitutions. However, studies in angiosperms [6], reptiles [7], and birds [7,8] have found a correlation between synonymous substitutions and net diversification, leading to the suggestion that the link between molecular rates and net diversification may be driven by the mutation rate.

Here, we focus on the rate of molecular evolution in chloroplast genes. Genetic changes in chloroplast genomes have been implicated in the process of speciation in plants. Coevolution between organelle and nuclear genomes has been recognized as an important factor in plant diversification [26]. Plastome-genome incompatibility can cause hybrid sterility or inviability, by disrupting sexual reproduction, leaf morphologies, and machineries for photosynthesis or respiration [27-29]. Some of the genetic events in chloroplasts that produce these aberrations are gene duplications, loss of gene complexes and genome rearrangements [26,30,31]. The resulting incompatibilities are probably generalized phenomena in plants, and the evolutionary consequence is that they can enhance post-zygotic barriers during speciation $[26,29,32,33]$. It seems possible, then, that variation in rates of molecular evolution of chloroplasts could also influence the speed of genetic isolation, and hence the diversification rate of plant lineages.

Using a phylogenetic comparative analysis of sister pairs [34], we investigated the relationship between rates of molecular evolution and net diversification in chloroplast genes of the plant family Proteaceae. This highly diverse family is mostly restricted to the Southern Hemisphere. It contains 79 recognized genera and around 1600 species, and some of its most diverse groups are the Australian genus Banksia and the African genus Protea. The high diversity of Proteaceae makes it a particularly attractive case study for diversification (e.g. [35-37]). In addition, the family has stark contrasts in species-richness between genera even within its biodiversity hotspots [38]. Of particular interest to this study are the numerous cases of monophyletic sister clades with remarkable differences in number of species. For example, the genus Protea has 112 species, while its sister genus Faurea has 15, and the Banksia lineage (including the dryandras) has 169 species while its sister 
lineage of the genera Austromuellera and Musgravea contains only 4 .

We focus on the rates of evolution of six chloroplast genes available for a genus level phylogeny of the family Proteaceae [38]. We use three protein-coding genes to estimate and contrast rates of synonymous (dS) and nonsynonymous $(\mathrm{dN})$ substitutions. Comparing $\mathrm{dN}, \mathrm{dS}$, and $\omega$ (dN/dS) to species-richness of clades allows us to separate the effect of mutation rate on net diversification from the effect of selection and effective population size. In this way, we aim to provide insight into the factors underlying the correlation between rates of molecular evolution and net diversification.

\section{Results}

A model where every branch in the phylogeny had an independent rate of substitutions had a significantly higher likelihood than the constant rates model in all the rates estimations (all substitutions, $\mathrm{dN}, \mathrm{dS}$ ), and $\omega$ ( $\mathrm{P}$ value < 0.01 for all tests; see Methods section), indicating that the rate of molecular evolution of the chloroplast genes analysed varies significantly between lineages of the family Proteaceae.

Species-rich lineages had significantly longer branch lengths in the phylogeny estimated from the full 6-gene dataset (one-tailed Wilcoxon Signed-Rank test, $\mathrm{W}=175$, $\mathrm{P}=0.0036$ ). This is evidence of a positive association between net diversification and the rate of molecular evolution of chloroplasts in the family Proteaceae. We also found significant differences in estimates of synonymous (dS: $\mathrm{W}=152, \mathrm{P}=0.041$ ), and non-synonymous rates (dN: $\mathrm{W}=165, \mathrm{P}=0.012$ ). However, we did not find a significant differences in estimates of $\omega$ between speciesrich and species-poor sister lineages ( $\mathrm{W}=100, \mathrm{P}=0.14$ ).

\section{Discussion}

We found a significant positive association between the rate of molecular evolution in chloroplast genes and species-richness in the plant family Proteaceae. There were significant associations between both synonymous and non-synonymous rates of substitutions and net diversification, but not between $\omega(\mathrm{dN} / \mathrm{dS})$ and diversification. The pattern of correlations in this study are consistent with other studies of angiosperms [6,39], reptiles, and birds $[7,8,10]$. Importantly, our results give some insight into the cause of this relationship. The variation in both synonymous and non-synonymous substitution rates between lineages may reflect a role for the rate of production of mutations in the chloroplast genome in the process of diversification in the Proteaceae. Because we fail to detect an increase in $\omega$ in species-rich clades, our analysis provides no tangible evidence for a role of selection or population size change in driving the relationship between substitution rates and diversification rates in this group.

\section{Synonymous substitutions and net diversification}

Synonymous substitution rates are typically interpreted to reflect the rate of production of mutations. Mutation rates are known to vary between lineages for a range of reasons. For example, species with shorter generation times tend to have faster mutation rates [23], presumably due to the accumulation of DNA replication errors [40]. Mutation rates can also vary across the genome, which may be at least in part due to differences in base composition or gene length $[24,41]$.

Since synonymous substitutions are commonly assumed to be functionally neutral, they are often used to provide a window into variation of mutation rates. However, bias in codon use can influence the synonymous rate if, for example, there is selection for efficiency in the process of translation [42]. This type of bias has been found in angiosperm mitochondrial genes although with selection that is so weak that it is considered not to affect estimations of mutation rates [43]. The chloroplast genome of angiosperms also has minimal codon bias and weak selection for translation efficiency [44]. Therefore, in this study, we consider that the relationship between synonymous substitution rate and net diversification is telling us something about the link between mutation and diversification, whether it reflects differences in the absolute mutation rate per unit time or in the differences in the distribution of fitness effects of synonymous mutations between lineages.

One explanation for the link between synonymous substitutions and net diversification is that higher mutation rates could cause faster genetic divergence between lineages. In this case, genes of chloroplast origin may be important because they can drive reproductive isolation in plants by interacting with nuclear alleles [25]. Reproductive barriers can occur due to the failure of interactions between nuclear and cytoplasmic gene complexes, for example cytoplasmic male sterility [45]. An increased mutation rate may generate more molecular changes that cause these phenomena, known as Bateson-Dobzhansky-Muller (BDM) incompatibilities, and so might accelerate postzygotic isolation $[16,46,47]$.

Some studies have found that lineage-specific variation in rates of molecular evolution are consistent across the nuclear, mitochondrial, and chloroplast genomes [48], so it may be that the increase in substitution rates that we detected also apply to the nuclear genomes of species-rich lineages in the Proteaceae. In this case, higher rates of substitution in the nuclear genome may be contributing to the formation of incompatibilities between diverging populations, either by generating BDM incompatibilities between the nuclear genomes or through interactions between the nuclear and organelle genomes.

Therefore, the association between the synonymous rate of chloroplast genes and diversification rate reported here 
may reflect the acceleration in the formation of postzygotic reproductive isolation. This is also consistent with our finding of an association between non-synonymous rates and net diversification because an increase in the mutation rate should also result in more effectively neutral non-synonymous substitutions going to fixation.

\section{Indirect links between diversification and the rate of molecular evolution}

An indirect relationship between the rate of molecular evolution and diversification could arise if some factor influenced both. For example, it has been suggested that tropical lineages have a higher rate of molecular evolution than their temperate counterparts [49]. This correlation might reflect a direct effect of temperature or UV light on mutagenesis [50], or an indirect effect if higher environmental energy leads to further growth rates and more rapid generation turnover, which could influence the mutation rate through accumulation of replication errors [23]. If higher growth rates also lead to faster diversification [51], then this could create an indirect link between the mutation rate and diversification. This may also explain the patterns in a study on angiosperms that investigated the correlations between species-richness, the rate of molecular evolution, and three energy variables (temperature, UV light, and evapotransportation), but which found no support for the mutation rate as the direct mediator of species-richness [21]. However, it is interesting to note that the Proteaceae do not appear to have higher rates of diversification in the tropics. Instead, much of their radiation has occurred in Mediterranean climate hotspots [38].

Life history variation provides another possible indirect link between rates of molecular evolution and diversification. Several studies have suggested that annual plants have a faster rate of molecular evolution than perennials, a pattern generally attributed to the generation time effect (see $[24,40])$. The potential for interactions between mechanisms that influence species-richness and the rate of molecular evolution has a broad scope and remains to be studied in detail.

\section{Net diversification and $\omega$}

It has been suggested that processes associated with speciation drive the link between rates of substitution and net diversification $[10,13,14]$, including diversifying selection and changes in effective population size. A reduction in effective population size $\left(N_{e}\right)$ may be caused by a speciation event that changes the population structure, such as vicariant or peripatric speciation [52]. This could lead to new adaptive pressures [53], or high levels of genetic drift in population bottlenecks [54]. These processes could increase the rate of fixation on non- synonymous substitutions, which may be reflected in an increase in $\omega(\mathrm{dN} / \mathrm{dS})[52,55,56]$.

Two studies on large numbers of phylogenies found a recurrent correlation between root-to-tip distances and the number of speciation events $[10,13]$. This result was interpreted as evidence that clades with more speciation events have a faster rate of molecular evolution, which they attributed to punctuational change associated with the founder-effect model of speciation. However, while these phylogenetic tests reveal an association between rates of evolution and number of phylogenetic nodes, they are not able to localise those changes to the nodes rather than the edges of the phylogeny, so cannot distinguish between two alternative explanations, that speciation events increase the substitution rate or that higher substitution rate increases diversification. One possible way to separate these models is in their predicted effects on the patterns of substitutions. If population divisions associated with speciation events have significant effects on rates of substitution, either through change in selection or reduction in effective population size, it should result in a relative increase in the nonsynonymous rate, reflected in an increase in $\mathrm{dN} / \mathrm{dS}(\omega)$.

We did not detect any association between $\omega$ and net diversification (see also [8]). This may be because net diversification is not associated with consistent effects on population size [46], or diversification does affect effective population size, but the effect on $\omega$ is overwritten by other population fluctuations [46]. Alternatively, the effect on reduction in effective population size may be too small to be detected or may be affected by the method of estimation of $\omega$ [57]. In theory, $N_{e}$ is an adequate representation of genetic drift in large populations and when the population size has been consistent for a long enough time [52]. It has even been shown that following transient increases in $N_{e}$ there can be an increase in the rate of substitutions due to slightly advantageous mutations, which is the opposite of the predicted effect [58]. Therefore, although $N_{e}$ is likely to have a significant effect on the rate of substitutions, predicting the form of the effect is far from a simple task [56]. Therefore, failure to detect an effect of population size changes of $\omega$ in this study does not imply that $N_{e}$ is unaffected by diversification; however, it does suggest that changes in $N_{e}$ during diversification are unlikely to explain the differences in substitution rates that we observe in these data.

\section{Molecular evolution and diversification in plants}

Many studies have focussed on identifying the genetic loci underlying speciation. These can be genes that contribute to the genetic isolation of populations, genes that drive differential ecological adaptation, and "magic traits" that do both (e.g. $[59,60])$. Genome-wide scans are increasingly being used to identify outlier loci that show signatures of 
selection, including loci that differ between pairs that are associated with floral traits, climatic factors, and sterility [61]. This study takes a different, and complementary, approach to analysing the role that the genome-wide generation of genetic change plays in diversification.

It is possible that higher mutation rates may create a greater pool of standing variation from which adaptive substitutions can be derived. The assumption that chloroplast genes do not play a direct role in ecological adaptation has now been challenged: for example, values of $\omega$ above 1 have been estimated in rbcL [62] and MatK sequences [63] for some linages, which was interpreted as a signal of positive selection. However, we did not find evidence of higher $\omega$ in more diverse clades for the loci analysed in this study, and the relationship between the amount of standing variation and diversification in plants is not clear. For example, studies have found that diversification in orchids is not associated with greater genetic diversity at the population level $[20,64]$.

Another scenario is that higher mutation rates contribute to the rate at which the genomes of different populations diverge and become gradually incompatible, making hybrids between the populations less fit. Bateson-Dozhansky -Muller (BDM) incompatibilities may arise from selection in different populations, but they might also be unconnected to ecological or behavioural divergence, in other words they may be "incidental on other acquired differences" [65]. For a mutation to go to substitution in one population, it must be broadly compatible with other common alleles in that population. But it will not have been "tested by natural selection" against alleles in isolated populations, and bringing those unharmonised alleles together may result in a maladapted individual [66]. The more unique substitutions each population has acquired, the greater the chance that a hybrid zygote will contain at least one pair of incompatible alleles. The steady increase in hybrid incompatibility with time in many species has been taken as evidence that many loci may contribute to BDM incompatibilities [47]. Under the BDM model, the rate of speciation may increase as the mutation rate increases [67]. Since the substitutions underlying BDM incompatibilities do not have to occur evenly in both lineages, a higher mutation rate in one lineage should drive divergence between them [47]. Debate continues over the rate at which hybrid incompatibility accumulates, particularly concerning the prediction that BDM incompatibilities should "snowball", accelerating relative to the substitution rate $[68,69]$.

Importantly, incompatibilities between populations can involve both organelle and nuclear genomes. Just as alleles within the nuclear genome must be able to work together to produce viable offspring, genomes of chloroplasts must be co-adapted to nuclear genome to allow normal development [70]. For example, alleles that cause cytoplasmic male sterility may be countered by suppression genes in the nuclear genome that restore male function, so a hybrid that inherited the organelle genome without the corresponding nuclear allele would be male sterile [33]. While cytonuclear conflict has been more frequently studied between mitochondrial and nuclear genomes, there is increasing evidence that incompatibilities between chloroplast and nuclear genomes contribute to hybrid incompatibility in many plant species [26].

Polyploidy is another important factor in the diversification of many plant lineages [71,72], but by focussing only on the chloroplast we minimized the impact of genome duplication on our analyses. Chloroplasts typically have uniparental inheritance, which simplifies the interpretation of the effects of genetic changes on divergence. However, the mode of inheritance of chloroplasts, whether inherited paternally or maternally, can vary between taxa, which can influence their levels of genetic diversity [73]. Chloroplast sequences should also limit the impact of "divergence hitchhiking", where linked neutral loci go to fixation through being linked to a locus under selection [61]. Lastly, while chloroplasts use recombination for genome repair [74], hybridization of chloroplasts from different lineages does not appear to be common [26,75].

\section{Conclusions}

We show a significantly faster rate of molecular evolution in chloroplast genes of species-rich lineages of the family Proteaceae. These results offer evidence for the influence of the rate of molecular evolution on diversification. This does not imply that the rate of molecular evolution explains the process of diversification, because this complex and heterogeneous process can be influenced by many mechanisms such as hybridization [76], polyploidy [77], allopatric events [14], and the duplication of genes [30]. However, the results do suggest that the substitution rate in chloroplasts may be one of these influences on the speed at which populations diverge, thus influencing the probability of populations becoming separate species [16].

\section{Methods}

\section{Sister pairs}

The phylogenetic analysis of the family Proteaceae by Sauquet et al. (2009) includes the 79 recognized genera and the species-richness for each genus compiled from the literature (references are also available in [78]). For the present study, monophyletic pairs of sister lineages that display differences in current species-richness were chosen from Sauquet et al's phylogeny. The main criterion to select pairs was that the pair was monophyletic, so the two sister lineages had the same amount of time to accumulate species diversity and substitutions, and each sister pair was phylogenetically independent from all other such pairs. 


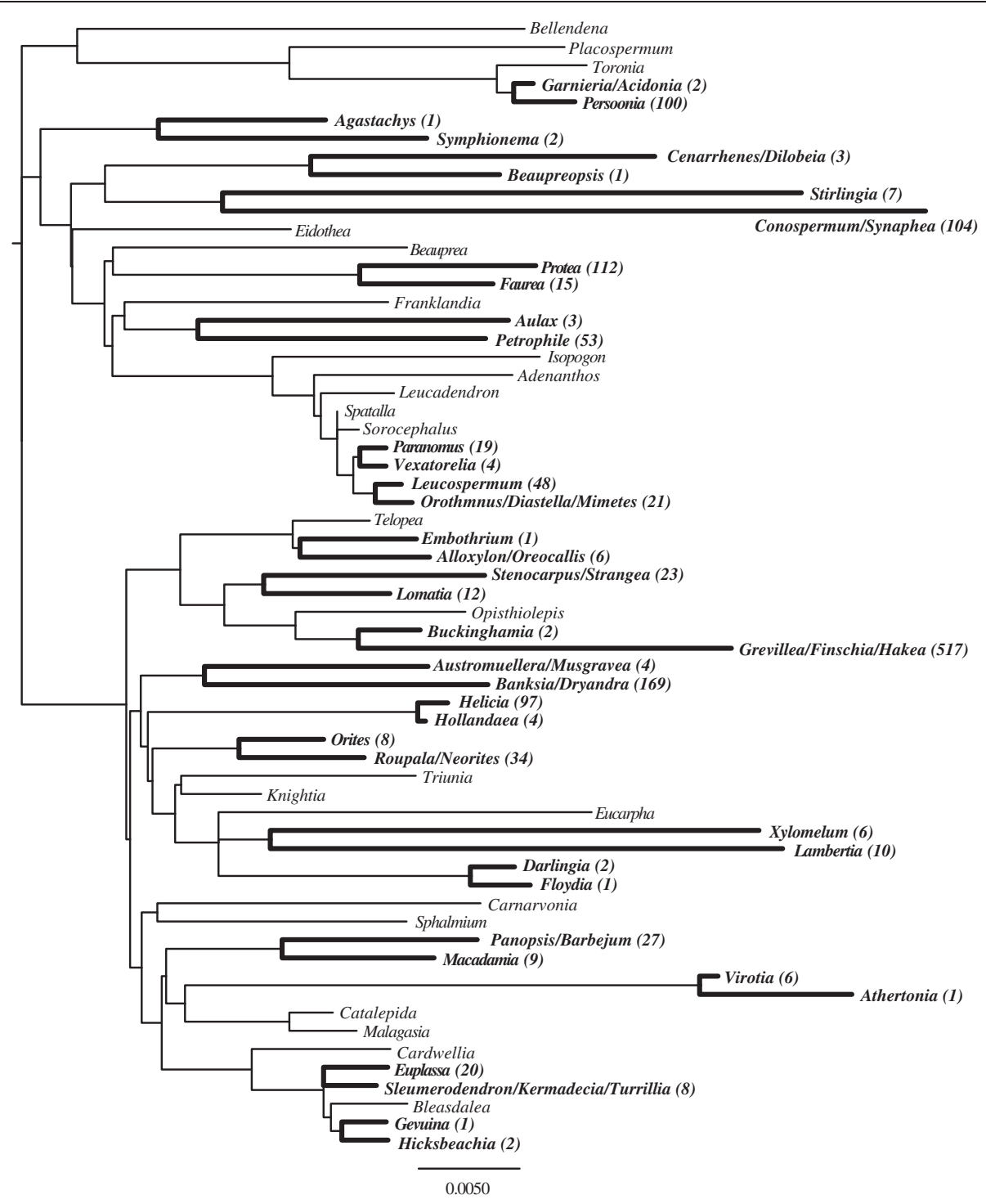

Figure 1 Phylogeny of Proteaceae with the sister pairs analysed in bold. Detailed legend: Molecular phylogeny of the family Proteaceae including the 20 sister pair groups used for the present analyses in bold. The branch lengths shown are proportional to the estimated number of substitutions as indicated by the whole dataset of six chloroplast genes. The species richness of the clades compared is shown in parentheses, with species numbers taken from Sauquet et al. (2009; references are also available in [78]). The scale bar indicates number of mutations.

We chose one genus to represent each sister lineage in order to avoid bias in branch length estimation due to the node density effect [79]. The chosen genus was the one with the greatest gene coverage. If the genera of a sister lineage had equal genetic coverage the genus was chosen at random. Using only one sequence per genus may reduce the power of the test, which may obscure a weak pattern; but using only one randomly selected species per sister lineage is unlikely to generate any systematic biases in rates, making this approach conservative for testing an association between rates of molecular evolution and net diversification (see $[8,11])$. In some cases a sister lineage is represented by combining sequences from several closely related genera. This practice increases our power to resolve the shared history of that lineage since its divergence from the common ancestor of the sister pair, and this is unlikely to create any systematic biases in rate estimations (Additional file 1: Table S1).

\section{Molecular dataset}

Branch length estimation was critical for comparative analyses in this study, so the genetic dataset required unambiguous genetic alignments and the maximum gene coverage of the species analysed. With these criteria we included six genes of chloroplast origin ( $a t p B, a t p B-r b c L$, 
Table 1 Genera of sister clades, and their corresponding species richness and branch length estimates

\begin{tabular}{|c|c|c|c|c|c|c|c|c|}
\hline Pair & Sister clades & Taxa & $\begin{array}{l}\text { Species } \\
\text { richness }\end{array}$ & $\begin{array}{c}\text { Genes } \\
\text { available }\end{array}$ & $\begin{array}{l}\text { Total branch } \\
\text { lengths }\end{array}$ & $\begin{array}{l}\text { dN branch } \\
\text { lengths }\end{array}$ & $\begin{array}{l}\text { dS branch } \\
\text { lengths }\end{array}$ & $\mathrm{dN} / \mathrm{dS}$ \\
\hline \multirow[t]{2}{*}{1} & Persoonia & Persoonia spp. & 100 & 2 & 0.00303 & 0.00331 & 0.00299 & 1.10704 \\
\hline & Garnieria + Acidonia & Garnieria spathulaefolia & 2 & & 0.00097 & 0.00105 & 0.00170 & 0.61562 \\
\hline \multirow[t]{2}{*}{2} & Symphionema & Symphionema montanum & 2 & 4 & 0.01329 & 0.00990 & 0.01713 & 0.57818 \\
\hline & Agastachys & Agastachys odorata & 1 & & 0.00828 & 0.00403 & 0.02123 & 0.18971 \\
\hline \multirow[t]{2}{*}{3} & Cenarrhenes + Dilobeia & Cenarrhenes nitida & 3 & 1 & 0.01703 & 0.00379 & 0.02849 & 0.13315 \\
\hline & Beaupreopsis & Beaupreopsis paniculata & 1 & & 0.00936 & 0.00315 & 0.01317 & 0.23892 \\
\hline \multirow[t]{2}{*}{4} & Conospermum + Synaphea & Conospermum spp. & 104 & 4 & 0.03480 & 0.01312 & 0.06744 & 0.19454 \\
\hline & Stirlingia & Stirlingia latifolia & 7 & & 0.02865 & 0.01164 & 0.05841 & 0.19922 \\
\hline \multirow[t]{2}{*}{5} & Protea & Protea cynaroides & 112 & 5 & 0.00872 & 0.00588 & 0.01364 & 0.43081 \\
\hline & Faurea & Faurea spp. & 15 & & 0.00660 & 0.00589 & 0.01052 & 0.55959 \\
\hline \multirow[t]{2}{*}{6} & Petrophile & Petrophile spp. & 53 & 3 & 0.01424 & 0.00723 & 0.02834 & 0.25512 \\
\hline & Aulax & Aulax spp. & 3 & & 0.01537 & 0.01279 & 0.02951 & 0.43337 \\
\hline \multirow[t]{2}{*}{7} & Paranomus & Paranomus spp. & 19 & 2 & 0.00130 & 0.00187 & $1.00 \mathrm{E}-09$ & $1.87 \mathrm{E}+06$ \\
\hline & Vexatorella & Vexatorella alpina & 4 & & 0.00130 & 0.00047 & 0.00445 & 0.10504 \\
\hline \multirow[t]{2}{*}{8} & Leucospermum & Leucospermum spp. & 48 & 2 & 0.00129 & 0.00095 & 0.00292 & 0.32577 \\
\hline & Orothamnus + Diastella + Mimetes & Mimetes spp. & 21 & & 0.00183 & 0.00187 & 0.00296 & 0.63319 \\
\hline \multirow[t]{2}{*}{9} & Alloxylon + Oreocallis & Alloxylon spp. & 6 & 4 & 0.00641 & 0.00418 & 0.00931 & 0.44871 \\
\hline & Embothrium & Embothrium coccineum & 1 & & 0.00577 & 0.00323 & 0.00625 & 0.51730 \\
\hline \multirow[t]{2}{*}{10} & Stenocarpus + Strangea & Stenocarpus salignus & 26 & 6 & 0.01094 & 0.00602 & 0.01962 & 0.30693 \\
\hline & Lomatia & Lomatia spp. & 12 & & 0.00625 & 0.00395 & 0.01304 & 0.30245 \\
\hline \multirow[t]{2}{*}{11} & Grevillea + Finschia + Hakea & Grevillea spp. & 515 & 6 & 0.01847 & 0.01027 & 0.03031 & 0.33881 \\
\hline & Buckinghamia & Buckinghamia spp. & 2 & & 0.00306 & 0.00118 & 0.00916 & 0.12925 \\
\hline \multirow[t]{2}{*}{12} & Virotia & Virotia leptophylla & 6 & 1 & 0.00091 & 0.00097 & $1.00 \mathrm{E}-09$ & $9.71 E+05$ \\
\hline & Athertonia & Athertonia diversifolia & 1 & & 0.00754 & 0.00535 & 0.01243 & 0.43028 \\
\hline \multirow[t]{2}{*}{13} & Panopsis + Brabejum & Panopsis spp. & 27 & 4 & 0.00966 & 0.00577 & 0.01995 & 0.28920 \\
\hline & Macadamia & Macadamia spp. & 9 & & 0.00752 & 0.00623 & 0.01371 & 0.45473 \\
\hline \multirow[t]{2}{*}{14} & Hicksbeachia & Hicksbeachia pinnatifolia & 2 & 1 & 0.00229 & 0.00261 & 0.00095 & 2.75046 \\
\hline & Gevuina & Gevuina avellana & 1 & & 0.00220 & 0.00098 & 0.00309 & 0.31894 \\
\hline \multirow[t]{2}{*}{15} & Euplassa & Euplassas occidentalis & 20 & 3 & 0.00318 & 0.00281 & 0.00448 & 0.62802 \\
\hline & $\begin{array}{l}\text { Sleumerodendron + Kermadecia + } \\
\text { Turrillia }\end{array}$ & $\begin{array}{l}\text { Sleumerodendron } \\
\text { austrocaledonicum + } \\
\text { Kermadecia pronyensis }\end{array}$ & 8 & & 0.00262 & 0.00199 & 0.00619 & 0.32064 \\
\hline
\end{tabular}


Table 1 Genera of sister clades, and their corresponding species richness and branch length estimates (Continued)

\begin{tabular}{|c|c|c|c|c|c|c|c|c|}
\hline \multirow[t]{2}{*}{16} & Banksia + Dryandra & Banksia spp. & 169 & 6 & 0.01403 & 0.00893 & 0.02906 & 0.30745 \\
\hline & Austromuellera + Musgravea & Austromuellera trinervia & 4 & & 0.01107 & 0.00525 & 0.02498 & 0.21017 \\
\hline \multirow[t]{2}{*}{17} & Roupala + Neorites & $\begin{array}{l}\text { Roupala montana + Roupala } \\
\text { monosperma }+ \text { Neorites } \\
\text { kevediana }\end{array}$ & 34 & 6 & 0.00620 & 0.00286 & 0.01367 & 0.20891 \\
\hline & Orites & Orites spp. & 8 & & 0.00420 & 0.00229 & 0.00483 & 0.47439 \\
\hline \multirow[t]{2}{*}{18} & Darlingia & Darlingia darlingiana & 2 & 2 & 0.00219 & 0.00236 & 0.00295 & 0.79752 \\
\hline & Floydia & Floydia praealta & 1 & & 0.00297 & 0.00132 & 0.00571 & 0.23042 \\
\hline \multirow[t]{2}{*}{19} & Lambertia & Lambertia spp. & 10 & 4 & 0.02536 & 0.01116 & 0.05726 & 0.19491 \\
\hline & Xylomelum & Xylomelum spp. & 6 & & 0.02419 & 0.01036 & 0.04448 & 0.23296 \\
\hline \multirow[t]{2}{*}{20} & Helicia & Helicia spp. & 97 & 3 & 0.00149 & 0.00094 & 0.00304 & 3.10E-01 \\
\hline & Hollandaea & Hollandaea riparia & 4 & & 0.00039 & 0.00000 & 0 & 0 \\
\hline
\end{tabular}

Detailed legend: Sister comparisons included in this analysis. For each pair, we list the two clades compared (a " + " indicates where more than one genus were combined as one sister lineage of a comparison). The taxon from which the sequence was taken is listed, with "spp" indicating that several congeneric sequences were combined (see Table S1 for details). The species richness for each sister lineage is taken from Sauque et al. (2009), and the number of available gene sequences for each comparison, out of the six chloroplast genes analysed in this study (See Additional file 1: Table S1). The estimated substitution rates for each sister lineage are given for Total branch lengths (all substitutions) as well as synonymous (dS) and non-synonymous (dN) substitutions, and estimates of $\omega$ (dN/dS). 
matK, $r b c L$, trnL intron, and $\operatorname{trnL}-\operatorname{trnF}$ ) from the data by Sauquet et al. 2009 and available in the GenBank repository (Additional file 1: Table S1). These were then aligned using the MUSCLE algorithm, checked by eye, and manually corrected using the program SeaView v4 [80]. This resulted in a 6278bp alignment with 62 taxa, 4457bp of exons, and 1821bp of introns (Additional file 1: Table S2).

\section{Phylogenetic estimation}

Each gene alignment was tested for the most appropriate model of substitutions using likelihood estimation and comparison with the Bayesian Information Criterion as implemented in the package "ape" [81] in R (The R Project - www.r-project.org/). Applying a partition by genes with the models selected (Additional file 1: Table S2), a maximum likelihood analysis with 1000 replicates was run using Garli v2.0 [82]. The resulting tree was then used to extract the branch length values of the sister pairs (Figure 1). If any of our chosen sister pairs were not monophyletic in our phylogeny they were excluded from the analysis. Twenty sister pairs of the initial twenty-two chosen from Sauquet at al's phylogeny were monophyletic in our estimates (Figure 1).

The inferred phylogenies (including those inferred for synonymous and non-synonymous substitutions; see next section) were examined for significant overall variation in branch lengths. To do this, we estimated the likelihoods of both a constant rates model and a free rates model (where there is one rate per branch) in the program HyPhy v2.1 [83], and compared them using a likelihood ratio test. If the free rates model provides a better fit for the data, this suggests significant variation in rates of molecular evolution across the phylogeny.

\section{$\mathrm{dN}$ and dS trees}

To examine the potential link between synonymous substitutions (dS), non-synonymous substitutions (dN), and $\omega(\mathrm{dN} / \mathrm{dS})$ and species-richness, we estimated $\mathrm{dN}$ and $\mathrm{dS}$ rates using an alignment of the coding genes (atpB, matK, and $r b c L$ ) in the program HyPhy v2.1 [83] with the MG94 model of codon evolution [84]. For the estimation of $\mathrm{dN}$ and $\mathrm{dS}$ trees, the MG94 model can be combined with any of the nucleotide substitution models nested in GTR + G + I. To choose the best combination we first gave HyPhy v2.0 a notation to estimate the codon frequencies (the frequency of each of the four bases in each of the three codon positions), which was a $3 \times 4$ matrix. Then the likelihood of each of the 203 possibilities was estimated and one was chosen according to the Akaike Information Criterion. The model chosen had four parameters, where $\theta_{\mathrm{AG}}=\theta_{\mathrm{CT}}$ and $\theta_{\mathrm{CG}}=\theta_{\mathrm{GT}}$, and its label in HyPhy v2.0 is MG94_3x4_012313. Finally, these parameters were optimized with maximum likelihood, constraining the topology to that estimated from the full six-gene dataset (Figure 1). The output included the $\mathrm{dN}$ and dS branch lengths (Additional file 2: Figure S1 and Additional file 3: Figure S2 respectively), which were used to extract the branch lengths of sister pairs. Given that HyPhy v2.0 estimates the values of $\mathrm{dN}$ and $\mathrm{dS}$ as the expected number of substitutions per nucleotide per site, the values for $\omega$ were calculated as the ratio between the two estimates (dN/dS; Additional file 4: Figure S3).

\section{Statistics}

The total species-richness and the estimates of branch lengths (for all substitutions, $\mathrm{dN}$ and $\mathrm{dS}$ ) and $\omega$ were collected for each of the two lineages in the sister pairs (Table 1). As the sister lineages had the same amount of time to accumulate species and substitutions, we assumed that the branch length is proportional to the rate of molecular evolution of chloroplasts (reviewed in [34]). Similarly, we assumed that species-richness of each sister clade reflects the net diversification (speciation minus extinction) of that lineage since the last common ancestor of the sister pair.

We performed a one-tailed Wilcoxon Signed-Ranks test in $R$, which resembles the standard sign test but accounts for the magnitudes of the differences between matched lineages [85]. This test sets a sign to each pair by subtracting branch lengths in the direction from species-rich to species poor; we did not include the sister pairs with equal species-richness as these cannot be accommodated in the Wilcoxon Signed-Ranks test. Then, the absolute difference between the two values was used to rank the pairs (lowest difference has rank 1 and the highest rank is the number of pairs). Tied values receive as a rank the mean of the ranks they span. The ranks are then given the sign of the pair and then added to produce a W statistic [85].

\section{Availability of supporting data}

The dataset supporting the results of this article is publicly available in the GenBank repository, with the accession numbers listed in the Additional file 1: Table S1. Although the data was produced by several sources, it is summarized in Sauquet et al. (2009).

\section{Additional files}

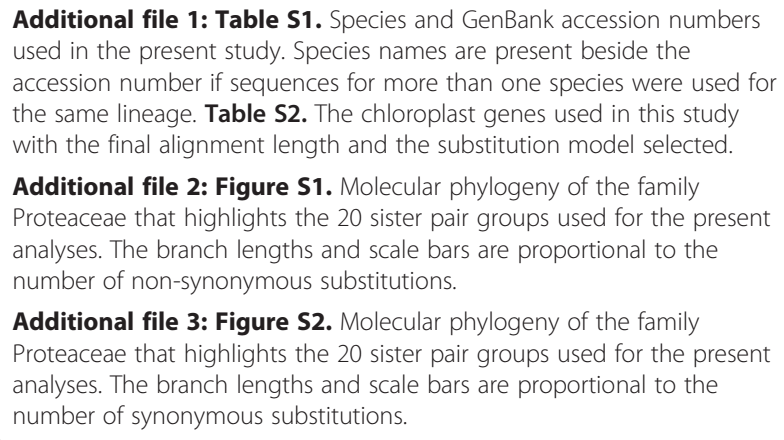

Additional file 3: Figure S2. Molecular phylogeny of the family Proteaceae that highlights the 20 sister pair groups used for the present analyses. The branch lengths and scale bars are proportional to the number of synonymous substitutions. 
Additional file 4: Figure S3. Molecular phylogeny of the family Proteaceae that highlights the 20 sister pair groups used for the present analyses. The branch lengths and scale bars are proportional to the $\mathrm{dN} /$ dS branch lengths calculated from the estimates of trees for $\mathrm{dN}$ and $\mathrm{dS}$ (Additional file 2: Figure S1 and Additional file 3: Figure S2).

\section{Competing interests}

Neither of the authors has received reimbursement, fees, funding, or salaries from any organisation that may gain or lose financially from the publication of this manuscript either now or in the future. This work was funded by the Australian Research Council. Neither of the authors do holds stocks or shares in an organisation that may gain or lose financially from the publication of this work either now or in the future. Neither of the authors hold or are currently applying for any patents related to this manuscript, nor have we received any reimbursements, fees, funding, or salaries related to patents for this publication. There are no financial or non-financial competing interests related to this manuscript.

\section{Authors' contributions}

David Duchene: ES \& FG. Lindell Bromham: ES \& FG. ES: Participated in the design of the study and performed statistical analyses. FG: conceived of the study, and participated in its design and coordination and helped to draft the manuscript. All authors read and approved the final manuscript.

\section{Acknowledgements}

We would like to thank Marcel Cardillo and Sebastian Duchene for the helpful discussions regarding the methods used in this work. This work was funded by the Australian Research Council.

Received: 4 December 2012 Accepted: 7 March 2013

Published: 13 March 2013

\section{References}

1. Huey RB: Rapid evolution of a geographic cline in size in an introduced fly. Science 2000, 287:308-309.

2. Rieseberg LH, Wendel J: Plant speciation - rise of the poor cousins. New Phytol 2003, 161:3-8.

3. Wu Cl, Ting CT: Genes and speciation. Nat Rev Genet 2004, 5:114-122.

4. Allen Orr H: The genetics of species differences. Trends Ecol Evol 2001, 16:343-350.

5. Barraclough TG, Harvey PH, Nee S: Rate of rbcL gene sequence evolution and species diversification in flowering plants (Angiosperms). Proc Roc Soc B Bio 1996, 263:589-591.

6. Barraclough $T$, Savolainen V: Evolutionary rates and species diversity in flowering plants. Evolution 2001, 55:677-683.

7. Eo SH, DeWoody JA: Evolutionary rates of mitochondrial genomes correspond to diversification rates and to contemporary species richness in birds and reptiles. Proc Roc Soc B Bio 2010, 277:3587-3592.

8. Lanfear R, Ho SYW, Love D, Bromham L: Mutation rate is linked to diversification in birds. Proc Natl Acad Sci 2010, 107:20423-20428.

9. Fontanillas $\mathrm{E}$, Welch JJ, Thomas JA, Bromham L: The influence of body size and net diversification rate on molecular evolution during the radiation of animal phyla. BMC Evol Biol 2007, 7:95.

10. Webster AJ, Payne RJH, Pagel M: Molecular phylogenies link rates of evolution and speciation. Science 2003, 301:478

11. Goldie X, Lanfear R, Bromham L: Diversification and the rate of molecular evolution: no evidence of a link in mammals. BMC Evol Biol 2011, 11:286

12. Rieseberg LH, Blackman BK: Speciation genes in plants. Ann Bot 2010, 106:439-455.

13. Pagel M, Venditti C, Meade A: Large punctuational contribution of speciation to evolutionary divergence at the molecular level. Science 2006, 314:119-121

14. Venditti $\mathrm{C}$, Pagel $\mathrm{M}$ : Speciation as an active force in promoting genetic evolution. Trends Ecol Evol 2010, 25:14-20

15. Woolfit M, Bromham L: Increased rates of sequence evolution in endosymbiotic bacteria and fungi with small effective population sizes. Mol Biol Evol 2003, 20:1545-1555.

16. Orr $\mathrm{H}$, Turelli $\mathrm{M}$ : The evolution of postzygotic isolation: accumulating Dobzhansky-Muller incompatibilities. Evolution 2001, 55:1085-1094.
17. Eo SH, Wares JP, Carroll JP: Population divergence in plant species reflects latitudinal biodiversity gradients. Biol Letters 2008, 4:382-384.

18. Schluter D, Conte GL: Genetics and ecological speciation. Proc Natl Acad Sci 2009, 106:9955-9962.

19. Spielman D, Brook BW, Frankham R: Most species are not driven to extinction before genetic factors impact them. Proc Natl Acad Sci 2004 101:15261-15264.

20. Kisel Y, Moreno-Letelier A, Bogarín D: Testing the link between population genetic differentiation and clade diversification in Costa Rican orchids. Evolution 2012, 66:3035-3052.

21. Davies TJ, Savolainen V, Chase MW, Moat J, Barraclough TG: Environmental energy and evolutionary rates in flowering plants. Proc Roc Soc B Bio 2004, 271:2195-2200.

22. Verdú M: Age at maturity and diversification in woody angiosperms. Evolution 2002, 56:1352-1361

23. Smith SA, Donoghue MJ: Rates of molecular evolution are linked to life history in flowering plants. Science 2008, 322:86-89.

24. Gaut B, Yang L, Takuno S, Eguiarte LE: The patterns and causes of variation in plant nucleotide substitution rates. Annu Review Ecol Syst 2011, 42:245-266

25. Kimura M: The Neutral Theory of Molecular Evolution. Cambridge, UK: Cambridge University Press; 1985.

26. Greiner S, Rauwolf U, Meurer J, Herrmann RG: The role of plastids in plant speciation. Mol Ecol 2011, 20:671-691

27. Kirk JTO, Tilney-Bassett RAE: The plastids. Their chemistry, structure, growth and inheritance. London \& San Francisco: WH Freeman \& Co.; 1967.

28. Stubbe W: Oenothera-An ideal system for studying the interactions of genome and plastome. Plant Mol Biol Rep 1989, 7:245-257.

29. Levin D: The cytoplasmic factor in plant speciation. Syst Bot 2003, 28:5-11

30. Xiong AS, Peng RH, Zhuang J, Gao F, Zhu B, Fu XY, Xue Y, Jin XF, Tian YS, Zhao W, Yao QH: Gene duplication, transfer, and evolution in the chloroplast genome. Biotechnol Adv 2009, 27:340-347.

31. Wicke S, Schneeweiss GM, DePamphilis CW, Müller KF, Quandt D: The evolution of the plastid chromosome in land plants: gene content, gene order, gene function. Plant Mol Biol 2011, 76:273-297.

32. Herrmann RG, Maier RM, Schmitz-Linneweber C: Eukaryotic genome evolution: rearrangement and coevolution of compartmentalized genetic information. Philos T Roy Soc B 2003, 358:87-97.

33. Johnson NA: Hybrid incompatibility genes: remnants of a genomic battlefield? Trends Genet 2010, 26:317-325.

34. Lanfear $\mathrm{R}$, Welch JJ, Bromham L: Watching the clock: studying variation in rates of molecular evolution between species. Trends Ecol Evol 2010, 25:495-503.

35. Cowling RM, Lamont BB: On the nature of Gondwanan species flocks: diversity of proteaceae in Mediterranean South-western Australia and South Africa. Aust J Bot 1998, 46:335.

36. Valente LM, Reeves G, Schnitzler J, Mason IP, Fay MF, Rebelo TG, Chase MW, Barraclough TG: Diversification of the African genus Protea (Proteaceae) in the Cape biodiversity hotspot and beyond: equal rates in different biomes. Evolution 2010, 64:745-760

37. Prunier R, Holsinger KE: Was it an explosion? Using population genetics to explore the dynamics of a recent radiation within Protea (Proteaceae L.). Mol Ecol 2010, 19:3968-3980.

38. Sauquet $\mathrm{H}$, Weston PH, Anderson CL, Barker NP, Cantrill DJ, Mast AR, Savolainen V: Contrasted patterns of hyperdiversification in Mediterranean hotspots. Proc Natl Acad Sci 2009, 106:221-225.

39. Lancaster LT: Molecular evolutionary rates predict both extinction and speciation in temperate angiosperm lineages. BMC Evol Biol 2010, 10:162.

40. Bromham $L:$ Why do species vary in their rate of molecular evolution? Biol Letters 2009, 5:401-404.

41. Yang L, Gaut BS: Factors that contribute to variation in evolutionary rate among Arabidopsis genes. Mol Biol Evol 2011, 28:2359-2369.

42. Ikemura T: Codon usage and tRNA content in unicellular and multicellular organisms. Mol Biol Evol 1985, 2:13-34.

43. Sloan DB, Taylor DR: Testing for selection on synonymous sites in plant mitochondrial DNA: the role of codon bias and RNA editing. I Mol Evol 2010, 70:479-491.

44. Morton BR: Selection on the codon bias of chloroplast and cyanelle genes in different plant and algal lineages. J Mol Evol 1998, 46:449-459.

45. Fishman $\mathrm{L}$, Willis $\mathrm{JH}: \mathrm{A}$ cytonuclear incompatibility causes anther sterility in Mimulus hybrids. Evolution 2006, 60:1372-1381. 
46. Rieseberg LH, Willis JH: Plant speciation. Science 2007, 317:910-914.

47. Welch J: Accumulating Dobzhansky-Muller incompatibilities: reconciling theory and data. Evolution 2004, 58:1145-1156.

48. Eyre-Walker A, Gaut BS: Correlated rates of synonymous site evolution across plant genomes. Mol Biol Evol 1997, 14:455-460.

49. Wright S, Keeling J, Gillman L: The road from Santa Rosalia: a faster tempo of evolution in tropical climates. Proc Natl Acad Sci 2006, 103:7718-7722.

50. Allen AP, Brown JH, Gillooly JF: Global biodiversity, biochemical kinetics, and the energetic-equivalence rule. Science 2002, 297:1545-1548.

51. Rohde K: Latitudinal gradients in species diversity: the search for the primary cause. Oikos 1992, 65:514-527.

52. Charlesworth B: Fundamental concepts in genetics: effective population size and patterns of molecular evolution and variation. Nat Rev Genet 2009, 10:195-205.

53. Lee CE: Evolutionary genetics of invasive species. Trends Ecol Evol 2002, 17:386-391.

54. Carson HL, Templeton AR: Genetic Revolutions in Relation to Speciation Phenomena: The Founding of New Populations. Annu Rev Ecol Syst 1984 15:97-132.

55. Ohta T: The nearly neutral theory of molecular evolution. Annu Rev Ecol Syst 1992, 23:263-286.

56. Woolfit M: Effective population size and the rate and pattern of nucleotide substitutions. Biol letters 2009, 5:417-420.

57. Eyre-Walker A: The genomic rate of adaptive evolution. Trends Ecol Evol 2006, 21:569-575.

58. Charlesworth J, Eyre-Walker A: The other side of the nearly neutral theory, evidence of slightly advantageous back-mutations. Proc Natl Acad Sci 2007, 104:16992-16997.

59. Servedio MR, Van Doorn GS, Kopp M, Frame AM, Nosil P: Magic traits in speciation: "magic" but not rare? Trends Ecol Evol 2011, 26:389-397.

60. Nosil P, Schluter D: The genes underlying the process of speciation. Trends Ecol Evol 2011, 26:160-167.

61. Strasburg JL, Sherman NA, Wright KM, Moyle LC, Willis JH, Rieseberg LH: What can patterns of differentiation across plant genomes tell us about adaptation and speciation? Philos T Roy Soc B 2012, 367:364-373.

62. Kapralov MV, Filatov DA: Widespread positive selection in the photosynthetic Rubisco enzyme. BMC Evol Biol 2007, 7:73.

63. Hao DC, Chen SL, Xiao PG: Molecular evolution and positive Darwinian selection of the chloroplast maturase matK. J Plant Res 2010, 123:241-247.

64. Phillips $R$, Dixon K, Peakall R: Low population genetic differentiation in the Orchidaceae: implications for the diversification of the family. Mol Ecol 2012, 21:5208-5220.

65. Darwin C: On the Origins of Species by Means of Natural Selection. London: John Murray; 1859

66. Presgraves DC: Speciation genetics: search for the missing snowball. Current Biol 2010, 20:1073-1074.

67. Gavrilets S: Perspective: Models of speciation: What have we learned in 40 years? Evolution 2003, 57:2197-2215.

68. Gourbière $\mathrm{S}$, Mallet J: Are species real? The shape of the species boundary with exponential failure, reinforcement, and the "missing snowball". Evolution 2010, 64:1-24.

69. Matute DR, Butler IA, Turissini DA, Coyne JA: A test of the snowball theory for the rate of evolution of hybrid incompatibilities. Science 2010, 329:1518-1521.

70. Moison M, Roux F, Quadrado M, Duval R, Ekovich M, Lê D-H, Verzaux M, Budar F: Cytoplasmic phylogeny and evidence of cyto-nuclear coadaptation in Arabidopsis thaliana. Plant J 2010, 63:728-738.

71. Abbott R, Albach D, Ansell S, Arntzen JW, Baird SJE, Bierne N, Boughman J, Brelsford A, Buerkle CA, Buggs R, Butlin RK, Dieckmann U, Eroukhmanoff F, Grill A, Cahan SH, Hermansen JS, Hewitt G, Hudson AG, Jiggins C, Jones J, Keller B, Marczewski T, Mallet J, Martinez-Rodriguez P, Möst M, Mullen S, Nichols R, Nolte AW, Parisod C, Pfennig K, et al: Hybridization and speciation. J Evol Bio 2013, 26:229-246.

72. Ainouche ML, Jenczewski E: Focus on polyploidy. New Phytol 2010, 186:1-4.

73. Petit RJ, Duminil J, Fineschi S, Hampe A, Salvini D, Vendramin GG: Comparative organization of chloroplast, mitochondrial and nuclear diversity in plant populations. Mol Ecol 2005, 14:689-701.

74. Maréchal A, Brisson N: Recombination and the maintenance of plant organelle genome stability. New Phytol 2010, 186:299-317.
75. Bock R: The give-and-take of DNA: horizontal gene transfer in plants. Trends Plant Sci 2010, 15:11-22.

76. Mallet J: Hybrid speciation. Nature 2007, 446:279-283.

77. Soltis DE, Albert VA, Leebens-Mack J, Bell CD, Paterson AH, Zheng C, Sankoff D, Depamphilis CW, Wall PK, Soltis PS: Polyploidy and angiosperm diversification. Am J Bot 2009, 96:336-348.

78. Weston P, Barker N: A new suprageneric classification of the Proteaceae, with an annotated checklist of genera. Telopea 2006, 11:314-344.

79. Hugall AF, Lee MSY: The likelihood node density effect and consequences for evolutionary studies of molecular rates. Evolution 2007, 61:2293-2307.

80. Gouy M, Guindon S, Gascuel O: SeaView version 4: A multiplatform graphical user interface for sequence alignment and phylogenetic tree building. Mol Biol Evol 2010, 27:221-224.

81. Paradis E, Claude J, Strimmer K: APE: Analyses of Phylogenetics and Evolution in R language. Bioinformatics 2004, 20:289-290.

82. Zwickl DJ: GARLI: genetic algorithm for rapid likelihood inference. 2006. https://www.nescent.org/wg_garli/.

83. Pond SLK, Frost SDW, Muse SV: HyPhy: hypothesis testing using phylogenies. Bioinformatics 2005, 21:676-679.

84. Muse S, Gaut B: A likelihood approach for comparing synonymous and nonsynonymous nucleotide substitution rates, with application to the chloroplast genome. Mol Biol Evol 1994, 11:715-724.

85. Wilcoxon F, Katti SK, Wilcox RA: Critical Values and Probability Levels for the Wilcoxon Rank Sum Test and the Wilcoxon Signed Rank Test. American Cyanamid: Lederle Laboratories Division; 1963.

doi:10.1186/1471-2148-13-65

Cite this article as: Duchene and Bromham: Rates of molecular evolution and diversification in plants: chloroplast substitution rates correlate with species-richness in the Proteaceae. BMC Evolutionary Biology 2013 13:65.

\section{Submit your next manuscript to BioMed Central and take full advantage of:}

- Convenient online submission

- Thorough peer review

- No space constraints or color figure charges

- Immediate publication on acceptance

- Inclusion in PubMed, CAS, Scopus and Google Scholar

- Research which is freely available for redistribution 